\title{
TAS05567, a Novel Potent and Selective Spleen Tyrosine Kinase Inhibitor, Abrogates Immunoglobulin-Mediated Autoimmune and Allergic Reactions in Rodent Models ${ }^{\mathbb{}}$
}

\author{
Hiroaki Hayashi, Ryusuke Kaneko, Shunsuke Demizu, Daichi Akasaka, Manabu Tayama, \\ Takafumi Harada, Hiroki Irie, Yoshio Ogino, Naoko Fujino, and Eiji Sasaki \\ Discovery and Preclinical Research Division, Taiho Pharmaceutical Co., Ltd., Tsukuba, Ibaraki, Japan
}

Received February 1, 2018; accepted May 1, 2018

\begin{abstract}
Spleen tyrosine kinase (Syk) is involved in regulation of B-cell receptor (BCR) and Fc receptor downstream signal pathways. Syk plays an essential role in production of inflammatory mediators and differentiation in various immune cells and is therefore an attractive target for treating inflammatory conditions, such as autoimmune and allergic diseases. We identified TAS05567 as a highly selective Syk inhibitor and evaluated its therapeutic potential in animal models. In vitro biochemical assays were performed with available kinase assay panels. Inhibitory effects of TAS05567 on immune cells were analyzed by assessing the Syk downstream signaling pathway and production of inflammatory factors. In vivo effects of TAS05567 were evaluated in animal models of autoimmune diseases and antigen-specific IgE transgenic mice. TAS05567 inhibited only 4 of 191 kinases tested but inhibited Syk enzymatic activity with
\end{abstract}

high potency. TAS05567 inhibited BCR-dependent signal transduction in Ramos cells, Fc $\gamma$ R-mediated tumor necrosis factor- $\alpha$ production in THP-1 cells, and FceR-mediated histamine release from RBL-2H3 cells. In rheumatoid arthritis models, TAS05567 suppressed hind-paw swelling in a dose-dependent manner compared with vehicle. Moreover, TAS05667 markedly reduced histopathologic scores in an established rat arthritis model. In a mouse immune thrombocytopenic purpura model, platelet counts were reduced with injection of anti-platelet antibody. TAS05567 prevented the platelet count decrease in a dosedependent manner. Finally, TAS05567 treatment suppressed IgE-mediated ear swelling in vivo. Collectively, our data indicate TAS05567 is a selective Syk inhibitor and potential therapeutic candidate for treating humoral immune-mediated inflammatory conditions such as autoimmune and allergic diseases.

\section{Introduction}

Autoimmune diseases, including rheumatoid arthritis (RA) and immune thrombocytopenia (ITP), are caused by aberrant immune responses that generally involve production of autoantibodies against autoantigens (Tan, 1989; Suurmond and Diamond, 2015). Various immune cells, including B-cells, monocytes, macrophages, and neutrophils, express receptors for the Fc portion of Ig molecules (Treanor, 2012; Guilliams et al., 2014). During the chronic inflammatory process of RA, immune complexes (ICs) formed by autoantigens and autoantibodies are deposited in synovial tissues and activate effector cells through the Fc-gamma receptor $(\mathrm{Fc} \gamma \mathrm{R})$, leading to synovial inflammation and joint

https://doi.org/10.1124/jpet.118.248153.

S This article has supplemental material available at jpet.aspetjournals.org. damage (Tan Sardjono et al., 2003). Whereas passive transfer of antibodies targeting type II collagen in mice produces pathologic joint changes resembling those in human RA (Banda et al., 2006), mice lacking Fc $\gamma \mathrm{R}$ do not develop inflammatory symptoms after antibody injection (Kagari et al., 2003). ITP is an autoimmune bleeding disorder in which opsonization by platelet-specific autoantibodies results in premature platelet destruction by macrophages (Crow and Lazarus, 2003; Arnold, 2015). Like RA, ICs have been implicated in the pathogenesis of ITP, because intravenous immunoglobulin (IVIg) targeting $F c \gamma R$ is effective in patients with ITP (Debre et al., 1993) and because injection of antibodies against platelet surface antigens decreases the platelet count, as in the pathogenesis of human ITP (Neschadim and Branch, 2016). On the basis of these findings, the Fc $\gamma \mathrm{R}$ signaling cascade has become an attractive target for treatment of RA and ITP.

\footnotetext{
ABBREVIATIONS: BCR, B-cell receptor; BLNK, B-cell linker protein; BSA, bovine serum albumin; CAIA, collagen antibody-induced arthritis; CIA, collagen-induced arthritis; COMP, cartilage oligomeric matrix protein; DNP, 2,4-dinitrophenyl; ELISA, enzyme-linked immunosorbent assay; FBS, fetal bovine serum; FcR, Fc receptor; IC I0 $_{50}$ median inhibitory concentration; ICs, immune complexes; ITP, immune thrombocytopenic purpura; IVIg, intravenous immunoglobulin; JAK, Janus kinase; LPS, lipopolysaccharide; M-CSF, macrophage colony-stimulating factor; MMP, matrix metalloproteinase; PE, phycoerythrin; PLC, phospholipase C; RA, rheumatoid arthritis; RANKL, receptor activator of nuclear factor $\kappa$ B ligand; $\mathrm{RFU}$, relative fluorescence units; $\mathrm{RT}$, room temperature; $\mathrm{R} 406,6$-(5-fluoro-2-(3,4,5-trimethoxyphenylamino) pyrimidin-4-ylamino)-2,2-dimethyl-2Hpyrido[3,2-b][1,4]oxazin-3(4H)-one; Syk, spleen tyrosine kinase; TAS05567, 3-([(3R,4R)-3-aminotetrahydro-2H-pyran-4-yl]amino)-5-([2-(tert-butyl)7-methyl-2H-indazol-5-yl]amino)-1,2,4-triazine-6-carboxamide; TNF, tumor necrosis factor; TNP, 2,4,6-trinitrophenol; TRAP, tartrate-resistant acid phosphate; VEGFR, vascular endothelial growth factor receptor.
} 
Allergic diseases are predominantly caused by antigenspecific IgE-mediated immune responses (Galli and Tsai, 2012). Antigen-induced crosslinking of IgE-bound FceRI leads to activation of mast cells and basophils followed by release of a variety of biochemical mediators, such as histamine and arachidonic acid metabolites (Stone et al., 2010). Importantly, FceRI-deficient mice fail to develop increased inflammatory responses even after repeated exposure to antigen (Taube et al., 2004). Omalizumab, a monoclonal antibody that inhibits the interaction between IgE and FceRI, has been shown effective in patients with severe allergic asthma (D'Amato et al., 2007). Therefore, targeting the FceRI signaling pathway is a promising therapeutic option for allergic diseases.

Spleen tyrosine kinase (Syk) is a nonreceptor cytoplasmic tyrosine kinase that is primarily expressed by cells of hematopoietic lineage (Turner et al., 2000). Syk acts downstream of immunoreceptor tyrosine-based activation motif-coupled receptors, including the $\mathrm{B}$-cell receptor (BCR), Fc receptors (FcRs), and integrin signaling, and influences diverse biologic events, such as cytokine production, degranulation, differentiation, and adhesion (Mocsai et al., 2010; Deng et al., 2016), suggesting that Syk is profoundly involved in the development of autoimmune and allergic diseases. For example, direct injection of Syk small-interfering RNA (siRNA) into the limb joints prevents joint swelling in models of autoantibodyinduced arthritis (Huang et al., 2013). In addition, Sykdeficient macrophages show severely impaired phagocytosis of IgG-opsonized particles in response to $\mathrm{Fc} \gamma \mathrm{R}$ activation (Kiefer et al., 1998). Regarding the relationship with allergic reactions, Syk-deficient mast cells fail to degranulate and secrete mediators when stimulated through FceRI (Costello et al., 1996). Considering its biologic actions and its association with the pathogenesis of autoimmune and allergic diseases, pharmacologic inhibition of Syk represents a potential therapeutic intervention option for patients with these diseases. Indeed, several ATP-competitive Syk inhibitors, notably fostamatinib (Rigel Pharmaceuticals), have already been evaluated in clinical trials performed in patients with autoimmune diseases, including RA and ITP (Bajpai, 2009). Even though fostamatinib was efficacious against chronic refractory ITP (Podolanczuk et al., 2009), it is unclear whether inhibition of Syk activity specifically contributed to the clinical response and adverse events observed in the clinical trials, as this drug inhibits several kinases, including vascular endothelial growth factor receptor (VEGFR) 2 and Janus kinase (JAK) 2 (Braselmann et al., 2006; Ferguson et al., 2016). Another Syk inhibitor (GS-9973, entospletinib, Gilead Sciences) has been developed for the treatment of leukemia, but it inhibits multiple protein kinases within 100-fold of its median inhibitory concentration $\left(\mathrm{IC}_{50}\right)$ value for Syk (Burke et al., 2014). These findings suggest that novel Syk inhibitors with activity profiles different from the above-mentioned inhibitors are required to provide new therapeutic options.

Against this background, we employed biochemical assays, cell-based assays, and animal models to characterize a novel, potent, and selective orally available Syk inhibitor: TAS05567. TAS05567 inhibited BCR-dependent cell signaling as well as FcR-mediated immune responses. Moreover, TAS05567 improved symptoms in representative rodent models of RA and ITP and suppressed ear swelling in antigen-specific IgE transgenic mice. Collectively, these findings identify TAS05567 as a potential lead candidate for further development of selective Syk inhibitors to treat Ig-mediated inflammatory conditions, including autoimmune and allergic diseases.

\section{Materials and Methods}

Synthesis of TAS05567. Experimental details and procedures for the preparation of 3-([(3R,4R)-3-aminotetrahydro-2H-pyran-4yl]amino)-5-([2-(tert-butyl)-7-methyl-2H-indazol-5-yl]amino)-1,2,4triazine-6-carboxamide (TAS05567) are described in Supplemental Fig. 1.

Reagents. R406 was purchased from Santa Cruz Biotechnology, Inc. (Dallas, TX). Prednisolone was purchased from MilliporeSigma (St. Louis, MO). Polyglobin N 10\% (IVIg) was obtained from Japan Blood Products Organization (Tokyo, Japan). For in vitro experiments, TAS05567 and R406 were dissolved in dimethyl sulfoxide. The reagents used to synthesize TAS05567 are described in supplementation experimental procedures.

Biochemical Assays. The Off-Chip Mobility Shift Assay was employed for measurement of kinase inhibitory activity. Recombinant FLT3, JAK2, VEGFR2, Syk, and RET (Carna Biosciences, Kobe, Japan) were used for activity assays in $20 \mathrm{mM}$ HEPES buffer (pH 7.5) with $0.01 \%$ Triton X-100 and $2 \mathrm{mM}$ dithiothreitol (Kitagawa et al., 2013). Each recombinant kinase was reacted with the appropriate peptide substrate in the presence of ATP at room temperature (RT), followed by measurement of the product ratio using the LabChip system (PerkinElmer, Waltham, MA). The selectivity of TAS05567 was assessed with a panel of 192 kinases using the Profiler Pro kit (PerkinElmer) according to the manufacturer's instructions. The plates were read using a LabChip EZ Reader (PerkinElmer).

Detection of B-Cell Linker Protein, Phospholipase C $\gamma 2$, and Extracellular Signal-Regulated Kinase Phosphorylation. A human B cell lymphoma cell line (Ramos, ATCC CRL-1596) was purchased from the American Type Culture Collection (Manassas, VA) and maintained in Roswell Park Memorial Institute-1640 medium (MilliporeSigma) containing $10 \%$ fetal bovine serum (FBS). Ramos cells $\left(1 \times 10^{5}\right.$ cells $\left./ 100 \mu \mathrm{l}\right)$ were pretreated with test compounds, followed by stimulation with goat $\mathrm{F}\left(\mathrm{ab}^{\prime}\right)_{2}$ anti-human IgM ( $5 \mu \mathrm{g} / \mathrm{ml}$; SouthernBiotech, Birmingham, AL) for 5 minutes at $37^{\circ} \mathrm{C}$. The cells were then fixed in Phosflow fix buffer I (BD Biosciences, San Jose, CA) for 10 minutes at $37^{\circ} \mathrm{C}$ and permeabilized in Phosflow perm buffer III (BD Biosciences) for 30 minutes on ice. After membrane permeabilization, the cells were washed in staining buffer (FBS) (BD Biosciences) and resuspended and incubated for 1 hour at $\mathrm{RT}$ in the same buffer containing phycoerythrin (PE)-labeled mouse anti-B-cell linker protein (BLNK) (pY84) (clone J117-1278), Alexa Fluor 647-labeled mouse anti-phospholipase C (PLC) $\gamma 2$ (pY759) (clone K86-689.37), and Alexa Fluor 488-labeled mouse antiextracellular signal-regulated kinase 1/2 (pT202/pY204) (clone 20A) (all from BD Biosciences). Subsequently, the cells were washed and resuspended in staining buffer (FBS) for flow cytometry using a FACSVerse flow cytometer (BD Biosciences).

Fc $\gamma$ R- and Lipopolysaccharide-Mediated Tumor Necrosis Factor- $\alpha$ Production Assay. To assess Fc $\gamma$ R-mediated tumor necrosis factor- $\alpha$ (TNF- $\alpha$ ) production, an Immulon 4 HBX 96-well plate (Thermo Fisher Scientific, Waltham, MA) was coated overnight at $4^{\circ} \mathrm{C}$ with $100 \mu \mathrm{g} / \mathrm{ml}$ of purified human IgG (R\&D Systems, Minneapolis, MN), and was washed with phosphate-buffered saline (PBS) (-) (Wako Pure Chemicals, Osaka, Japan). THP-1 cells (ATCC TIB-202) were seeded next into the IgG-coated plate at a density of $2 \times$ $10^{6}$ cells $/ \mathrm{ml}$ and incubated for 4 hours at $37^{\circ} \mathrm{C}$. To measure lipopolysaccharide (LPS)-mediated TNF production, THP-1 cells were seeded at the same density and pretreated with TAS05567 for 1 hour, followed by stimulation with LPS ( $1 \mu \mathrm{g} / \mathrm{ml}$; MilliporeSigma) for 24 hours at $37^{\circ} \mathrm{C}$. The TNF- $\alpha$ level in the supernatant was determined by enzyme-linked immunosorbent assay (ELISA) (R\&D Systems). 
FceRI-Mediated Calcium Flux and Histamine-Release Assay. The intracellular calcium level was determined using a FLIPR Calcium 6 Assay Kit (Molecular Devices, Sunnyvale, CA). RBL-2H3 cells (ATCC CRL-2256) were seeded overnight at $5 \times 10^{4}$ cells/well in a 96-well clear-bottomed plate with black walls in minimum essential media (MEM) containing 15\% FBS. After being washed with serumfree MEM, the cells were sensitized by incubation for 1 hour at $37^{\circ} \mathrm{C}$ with mouse anti-2,4-dinitrophenyl (DNP)-IgE $(0.3 \mu \mathrm{g} / \mathrm{ml}$; MilliporeSigma), followed by incubation with FLIPR Calcium 6 Assay kit dye and TAS05567 for 2 hours at $37^{\circ} \mathrm{C}$. DNP-bovine serum albumin (BSA) $(0.1 \mu \mathrm{g} / \mathrm{ml}$; LSL, Tokyo, Japan) was added and fluorescence as relative fluorescence units (RFUs) was detected every 30 seconds at an excitation wavelength of $485 \mathrm{~nm}$ and an emission wavelength of $525 \mathrm{~nm}$ using a FlexStation II (Molecular Devices). X $\eta \alpha \nu \gamma \varepsilon$ in RFU was calculated by subtracting the value at initiation of measurement.

For the histamine-release assay, RBL-2H3 cells were seeded overnight in a 96 -well plate $\left(2 \times 10^{4}\right.$ cells/well). After washing, the cells were sensitized by incubation with mouse anti-DNP-IgE $(0.3 \mu \mathrm{g} / \mathrm{ml})$ for 1 hour at $37^{\circ} \mathrm{C}$. The sensitized cells were then pretreated with TAS05567 for 1 hour, followed by stimulation with DNP-BSA $(0.1 \mu \mathrm{g} / \mathrm{ml})$ for 15 minutes at $37^{\circ} \mathrm{C}$ and measurement of histamine in the supernatant using a histamine enzyme immunoassay (EIA) kit (Medical \& Biologic Laboratories, Nagoya, Japan).

Differentiation of Osteoclasts. Primary human osteoclast precursor cells (Lonza, Walkersville, MD) were cultured according to the manufacturer's instructions. Macrophage colony-stimulating factor (33 ng/ml; M-CSF) and $66 \mathrm{ng} / \mathrm{ml}$ of receptor activator of nuclear factor $\kappa \mathrm{B}$ ligand (RANKL) (Lonza) were added next to the culture medium (OCP BulletKit Lonza; containing 10\% FBS). After differentiation of osteoclasts, staining was performed on day 5 using a tartrate-resistant acid phosphate (TRAP) staining kit (Cosmo Bio, Tokyo, Japan), and the number of mature osteoclasts (TRAP-positive multinucleated cells $>100 \mu \mathrm{m}$ in diameter) per well was determined by manual counting.

Experimental Animals. All animal experiments were approved by the Animal Experiments Ethics Committee of Taiho Pharmaceutical Co., Ltd. The animals used for the present study were $\mathrm{BALB} / \mathrm{c}$ (female and male) mice, male DBA1/J mice, female C57BL/ 6J mice, female Lewis rats, and male Sprague-Dawley rats from Charles River Laboratories Japan (Yokohama, Japan) and male 2,4,6-trinitrophenol (TNP)-specific IgE transgenic mice from CREA Japan (Tokyo, Japan). All animals were housed in cages and maintained under a 12-hour light/dark cycle with water and food supplied ad libitum. During the experimental period, the activity, feeding, and signs of pain of animals were assessed in accordance with the established protocol. For administration, TAS 05567 was dissolved in a solution of $0.5 \%$ hydroxypropyl methyl cellulose (Shinetsu Chemical, Tokyo, Japan) with $0.1 \mathrm{~N} \mathrm{HCl}$, and prednisolone (11 $\beta, 17 \alpha, 21$-trihydroxypregna-1,4-diene-3,20-dione) was suspended in a solution of $0.5 \%$ (hydroxypropyl)methyl cellulose (HPMC) without $\mathrm{HCl}$. IVIg $(500 \mathrm{mg} / 50 \mathrm{ml})$ was administered by intravenous injection at a volume of $10 \mathrm{ml} / \mathrm{kg}$.

BLNK Phosphorylation in Whole Blood. For analysis of phosphor-BLNK in mice, blood samples were collected into heparinized tubes from nonimmunized male BALB/c mice (7-9 weeks old), and then aliquots of the blood $(80 \mu \mathrm{l})$ were transferred to test tubes. TAS05567 was added and incubated for 30 minutes at the indicated concentrations prior to stimulation with goat anti-mouse IgD (1:100; Thermo Fisher Scientific) for 10 minutes at $37^{\circ} \mathrm{C}$. Stimulation was suppressed by addition of Lyse/Fix Buffer (BD Biosciences) according to the manufacturer's protocol. Fixed cells were incubated overnight at $4^{\circ} \mathrm{C}$ with PerCP-conjugated anti-mouse CD45R/B220 antibody (Clone RA3-6B2) (BD Biosciences) and PE-conjugated anti-BLNK antibody (pY84) (clone J117-1278).

For the experiment, blood samples of male Sprague-Dawley rats (7-8 weeks old) were collected into heparinized tubes, and then aliquots $(180 \mu \mathrm{l})$ of the blood were transferred to test tubes. TAS05567 was added and incubated for 1 hour prior to stimulation with anti-rat IgD (20 $\mu \mathrm{g} / \mathrm{ml}$; Thermo Fisher Scientific), and stimulation was suppressed by addition of Lyse/Fix Buffer (BD Biosciences). Fixed cells were incubated for 1 hour at RT with FITC-conjugated ant-rat CD45RA antibody (clone OX-33) (BD Biosciences) and PE-conjugated anti-BLNK antibody (pY84) (clone J117-1278). Phosphorylation of BLNK induced by anti-IgD antibody was quantified using a flow cytometer (BD Biosciences).

Pharmacokinetics. TAS05567 was orally administered to male $\mathrm{BALB} / \mathrm{c}$ mice at $10 \mathrm{mg} / \mathrm{kg}$ (dosing volume of $10 \mathrm{ml} / \mathrm{kg}$ ), and blood samples were collected with a heparinized syringe at $0.5,1,2,4$, and 6 hours after administration. In addition, TAS05567 was orally administered to male Sprague-Dawley rats at 10 or $25 \mathrm{mg} / \mathrm{kg}$ (dosing volume of $10 \mathrm{ml} / \mathrm{kg}$ ), and blood samples were collected at 1, 2, 4, 8, and 24 hours after administration. The blood samples were centrifuged at $10,000 \mathrm{~g}$ for 5 minutes at $4^{\circ} \mathrm{C}$ to obtain plasma, which was stored at $-80^{\circ} \mathrm{C}$ until use. Plasma drug concentrations were determined by liquid chromatography-tandem mass spectrometry.

Mouse Model of Collagen Antibody-Induced Arthritis. On day 0 , female $\mathrm{BALB} / \mathrm{c}$ mice (7-8 weeks old) were intravenously injected with $2 \mathrm{mg}$ of an arthritogenic cocktail containing five monoclonal antibodies (Chondrex, Redmond, WA), followed by intraperitoneal injection of LPS (100 $\mu \mathrm{g})$ on day 4. Mice were randomly divided into vehicle, prednisolone, and TAS05567 groups, and the test drugs were administered daily from day 0 . Arthritis was assessed on days 0 , 3,6 , and 9 using the following clinical scoring system: 0 , normal paw; 1 , one swollen digit; 2 , more than one swollen digit; 3 , swelling of the entire paw; 4, swelling of the paw and all digits. The maximum possible score was $16(4 \times 4$ paws $)$. Serum matrix metalloproteinase (MMP)-3 levels were determined by ELISA (R\&D Systems).

Rat Model of Established Collagen-Induced Arthritis. On day -14 , female Lewis rats ( 7 weeks old) were anesthetized with isoflurane and injected with incomplete Freund adjuvant (BD Biosciences) containing $2 \mathrm{mg} / \mathrm{ml}$ of bovine type II collagen at nine sites on the back and two on the tail ( $0.1 \mathrm{ml}$ per site), followed by booster injections at two sites on the tail $(0.1 \mathrm{ml}$ per site) on day -7 . Oral administration of TAS 05567 and prednisolone was initiated on day 1 of the study and continued to day 14 . The volume of both hind paws was measured on days 1,7 , and 14 by water displacement using a plethysmometer for rats (MK-101P; Muromachi Kikai, Tokyo, Japan). Body weight was also measured every day to monitor toxicity. At the end of the experiment, blood samples were collected for measurement of the red blood cell count and hemoglobin using a hematology autoanalyzer (Sysmex XT-2000iV; Sysmex, Kobe, Japan). In addition, the serum level of cartilage oligomeric matrix protein (COMP) was determined by ELISA using a kit from Immunodiagnostic Systems (Boldon, UK), and both hind paws were harvested for histopathologic examination.

Histopathologic Examination. Rat hind limbs were decalcified in formalin with $10 \%$ formic acid (Wako Pure Chemical Industries, Tokyo, Japan) and embedded in paraffin blocks, which were cut into sections, stained with hematoxylin-eosin, and randomly selected for microscopic examination. Hind limb joints were then evaluated by assigning a histopathologic score for each of four pathologic changes (inflammation, pannus, cartilage damage, and bone damage) on a 5 -grade scale from 0 to $4(0=$ normal and $4=$ the most severe changes). The histopathologic scores for each pathologic change were summed for both hind limbs to calculate the total score per animal (maximum: eight points).

Mouse Model of Immune Thrombocytopenia. Female C57BL/ 6J mice ( 8 weeks old) received TAS 05567 orally on days 1 and 2 . In the IVIg group, mice were injected intravenously with IVIg $(1 \mathrm{~g} / \mathrm{kg})$ on day 1 , followed by intravenous injection of $2 \mu \mathrm{g}$ of anti-CD41 antibody (clone MWReg30; Thermo Fisher Scientific) in $0.2 \mathrm{ml}$ of PBS on day 2. On day 3, $200 \mu \mathrm{l}$ of peripheral blood was collected in a $\mathrm{K}_{2}$ EDTA-coated Microtainer tube (BD, Franklin Lakes, NJ), and the platelet count was determined using a Sysmex XT-2000iV hematology autoanalyzer (Sysmex).

Mouse Model of Type I Allergy. Male TNP-specific IgE transgenic mice ( 7 weeks old) were epicutaneously administered $0.025 \%$ 
A

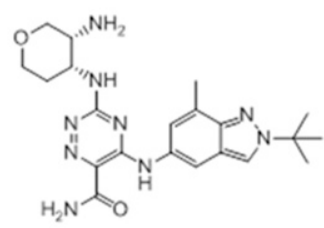

B

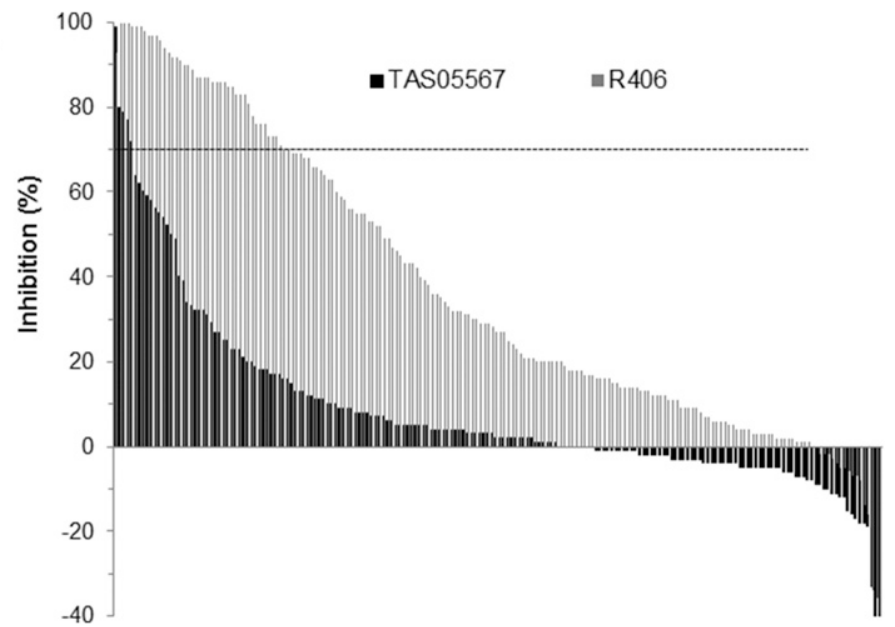

Fig. 1. Selectivity of TAS05567 and R406 against a panel of 192 kinases. (A) Chemical structure of TAS05567. (B) TAS05567 and R406 were evaluated using the Profiler Pro kit. Values represent percent inhibition at $50 \mathrm{nM}$ (TAS05567; approximately 140-fold the $\mathrm{IC}_{50}$ value of Syk kinase) and at $500 \mathrm{nM}$ (R406; approximately 40 -fold the $\mathrm{IC}_{50}$ value of Syk kinase). Inhibitory activity of $70 \%$ is shown as a dashed line.

picryl chloride (1-chloro-2,4,6-trinitrobenzene; Nakalai Tesuque, Kyoto, Japan) in acetone on both ears (10 $\mu$ l per ear). TAS05567 was administered orally to mice 30 minutes before antigen challenge. Ear thickness was measured using a dial thickness gauge G-2.4N (Ozaki, Tokyo, Japan) at 1, 2, 4, and 24 hours after antigen challenge. Difference in ear thickness (average value on the right and left) was calculated at each time point.

Statistical Analysis. Statistical analysis and determination of $\mathrm{IC}_{50}$ values were performed with EXSUS software, version 8.0.0 (CAC Exicare, Tokyo, Japan). Results are reported as mean \pm S.D. for in vitro experiments or mean \pm S.E.M. for in vivo experiments.

The efficacy of TAS05567 in the rodent inflammation models was evaluated using the Dunnett test, whereas the statistical significance of differences in histopathologic scores was assessed using the Steel test. In all analyses, $P<0.05$ was considered to indicate statistical significance.

\section{Results}

Potency and Selectivity of TAS05567. We synthesized a series of potent and highly selective ATP-competitive novel inhibitors of Syk. Investigation of structure-activity relationships led to identification of TAS05567 as a lead compound. The chemical structure of TAS05567 is shown in Fig. 1A. TAS05567 potently inhibited the activity of Syk, showing an average $\mathrm{IC}_{50}$ (mean \pm S.D.) of $0.37 \pm 0.029 \mathrm{nM}$ in enzymatic assays in the presence of ATP concentration close to the $\mathrm{K}_{\mathrm{m}}$ value. TAS05567 was more potent than R406 (an active metabolite of fostamatinib), exhibiting an average $\mathrm{IC}_{50}$ of $13 \pm 0.26 \mathrm{nM}$ under the same condition. The specificity of TAS05567 for Syk was determined at $50 \mathrm{nM}$ (approximately 140 times the $\mathrm{IC}_{50}$ value) using a panel of 192 kinases. In these analyses, TAS 05567 only showed $>70 \%$ inhibition of Syk and four other kinases (Fig. 1B; Supplemental Table 1). In comparison, R406 at $500 \mathrm{nM}$ (approximately 40 times its $\mathrm{IC}_{50}$ for Syk) showed $>70 \%$ inhibition of 43 of the 192 kinases. During clinical trials of fostamatinib in patients with RA, adverse events such as hypertension, neutropenia, and anemia were considered to be related to inhibition of VEGFR2 and JAK2 (Baluom et al., 2013; Ferguson et al., 2016). Accordingly, the $\mathrm{IC}_{50}$ values of TAS05567 and R406 were determined for four selected kinases, including VEGFR2 and JAK2.
TAS05567 showed at least 10 -fold selectivity for Syk over the four kinases, and R406 showed equal or greater efficacy against these kinases (Table 1). In addition, the enzymatic assays of Syk as well as the selected four kinases were performed at $1 \mathrm{mM}$ ATP to approximate cellular concentrations. In the presence of a physiologically relevant ATP concentration, TAS05567 inhibited Syk activity with $\mathrm{IC}_{50}$ of $1.5 \pm 0.40 \mathrm{nM}$ but much less activity against the four kinases (Table 1). Furthermore, the selectivity of TAS05567 for nonkinase targets was evaluated using a Panlabs Lead Profiling screen. In this assay, TAS05567 at $10 \mu \mathrm{M}$ only inhibited 1 of the 68 targets tested (inhibition of radioligand binding $>50 \%$ ) (Supplemental Table 2).

TAS05567 Inhibits BCR-Dependent Signaling and FcR-Dependent Functions. As Syk is a key mediator of BCR activation in B cells, we evaluated the effectiveness of TAS05567 in blocking the BCR-dependent signaling cascade. When Ramos cells (human B lymphoma cells) were pretreated with TAS05567 prior to BCR crosslinking by exposure to antiIgM, there was marked inhibition of the phosphorylation of BLNK, an adaptor protein phosphorylated by activated Syk (Fig. 2A). The $\mathrm{IC}_{50}$ of TAS05567 for suppressing induction of BLNK phosphorylation by anti-IgM was $1.8 \mathrm{nM}$, which was lower than that of R406 (Table 2). We also examined whether TAS05567 inhibited other downstream signaling molecules, including PLC $\gamma 2\left(\mathrm{IC}_{50}, 23 \mathrm{nM}\right)$ and extracellular signalregulated kinase $1 / 2\left(\mathrm{IC}_{50}, 9.8 \mathrm{nM}\right)$, after stimulation of Ramos

TABLE 1

Biochemical IC $_{50}$ values for TAS05567 and R406 against five kinases Values are mean or mean \pm S.D. for the $\mathrm{IC}_{50}$ values. Three independent experiments were performed to determine the $\mathrm{IC}_{50}$ values of Syk.

\begin{tabular}{|c|c|c|c|c|c|c|}
\hline \multirow{2}{*}{ Kinase } & \multirow{2}{*}{ ATP } & \multicolumn{2}{|c|}{$\mathrm{IC}_{50}$} & \multirow{2}{*}{ ATP } & \multicolumn{2}{|c|}{$\mathrm{IC}_{50}$} \\
\hline & & TAS05567 & R406 & & TAS05567 & R406 \\
\hline & $\mu M$ & $n M$ & $n M$ & $\mu M$ & $n M$ & $n M$ \\
\hline Syk & 26 & $0.37 \pm 0.029$ & $13 \pm 0.26$ & 1000 & $1.5 \pm 0.40$ & $67 \pm 14$ \\
\hline FLT3 & 94 & 10 & $<0.30$ & 1000 & 39 & 0.56 \\
\hline JAK2 & 13 & 4.8 & 0.86 & 1000 & 160 & 25 \\
\hline $\mathrm{KDR}$ & 74 & 600 & 9.8 & 1000 & 2600 & 42 \\
\hline RET & 7.5 & 29 & 2.8 & 1000 & 760 & 68 \\
\hline
\end{tabular}



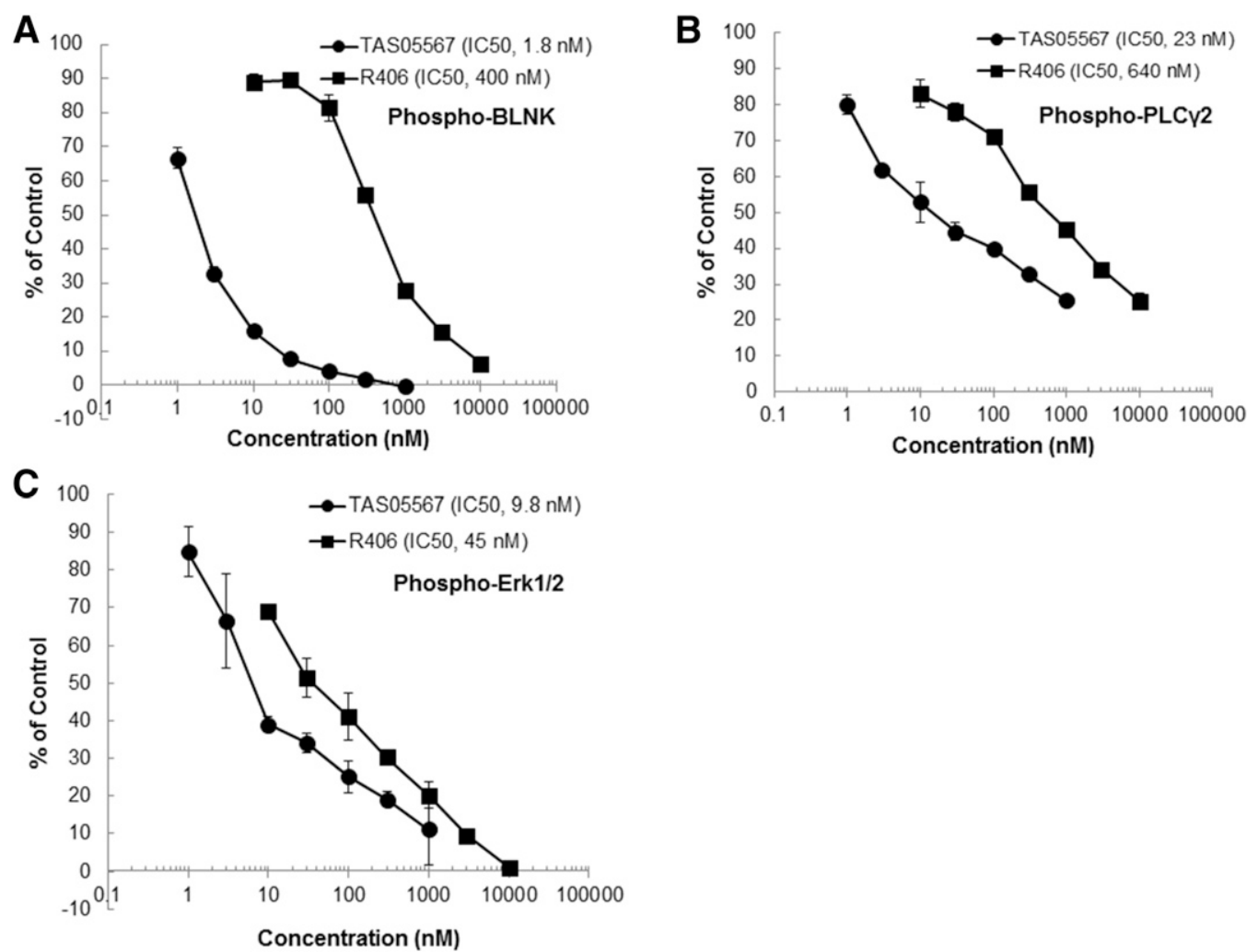

Fig. 2. Effects of TAS05567 and R406 on BCR-dependent signaling pathways. Ramos cells were activated with anti-human IgM F(ab' $)_{2}$ fragments for 10 minutes in the presence of increasing concentrations of TAS05567 or R406. The phosphorylation levels of BLNK (A), PLC $\gamma 2$ (B), and ERK 1/2 (C) were analyzed by flow cytometry. Values are presented as percent of mean fluorescence intensity relative to vehicle control cells (100\%) and nonstimulated control cells $(0 \%)$. Data were obtained from triplicate analyses and are presented as mean \pm S.D.

cells with anti-IgM (Fig. 2, B and C). TAS05567 showed stronger inhibition of these molecules in the BCR-dependent signaling cascade than R406.

Syk reportedly plays a central role in $\mathrm{Fc} \gamma \mathrm{R}$-mediated production of proinflammatory cytokines by monocytes and macrophages (Vogelpoel et al., 2015). Therefore, we evaluated the inhibitory effect of TAS05567 on IgG-induced TNF- $\alpha$ release by THP-1 cells. TAS05567 showed concentrationdependent inhibition of TNF- $\alpha$ production by THP-1 cells stimulated with IgG (Fig. 3A). In contrast, TAS05567 had minimal effect on LPS-induced production of TNF- $\alpha$ by these cells, as already reported (Liao et al., 2013). These finding suggest that TAS05567 specifically inhibits the Fc $\gamma$ Rmediated pathway. In addition, Syk-deficient mast cells from inducible Syk knockout mice generated using the Cre/loxP system showed no calcium flux or histamine release despite activation of FceRI (Wex et al., 2011). Therefore, we also evaluated the ability of TAS05567 to block FceR-mediated cellular functions by examining its effect on antigen-induced calcium flux and histamine release in IgE-sensitized RBL-2H3 cells (rat basophilic cells). TAS05567 suppressed both calcium flux $\left(\mathrm{IC}_{50}, 27 \mathrm{nM}\right)$ and histamine release $\left(\mathrm{IC}_{50}, 13 \mathrm{nM}\right)$ induced by crosslinking of $F c \varepsilon R I$ with IgE and antigen (Fig. 3, B and C).

TAS05567 Suppresses Development of TRAPPositive Multinucleated Cells. In addition to its crucial role in inflammation, Syk contributes directly to bone resorption in RA via its kinase activity-mediated regulation of receptor activator of nuclear factor $\kappa \mathrm{B}$ (RANK) signaling pathway that is essential for differentiation and activation of osteoclasts (Yamasaki et al., 2014). Therefore, we explored the effect of
TAS05567 on osteoclast differentiation using human osteoclast precursor cells. After precursor cells were cultured with the indicated concentrations of TAS05567 for four days in the presence of M-CSF and RANKL, development of TRAPpositive multinucleated mature osteoclasts was assessed on day 5 (Fig. 4A). TAS05567 inhibited the formation of mature osteoclasts in a concentration-dependent manner, and osteoclast differentiation was completely suppressed at $30 \mathrm{nM}$ (Fig. 4B).

TAS05567 Inhibits IgD-Induced BLNK Phosphorylation in Mouse and Rat Whole Blood. As plasma protein binding by drugs has a marked influence on drug activity in vivo, we performed whole-blood assays using samples from mice and rats to assess inhibition of BCR-dependent signal transduction as a surrogate pharmacodynamic marker for efficacy in animal models. After peripheral blood samples collected from mice or rats were pretreated with TAS05567 at the indicated concentrations, BLNK phosphorylation was assessed following stimulation with anti-IgD. TAS05567 inhibited anti-IgD-induced BLNK phosphorylation in the

TABLE 2

Effects of TAS05567 on BLNK phosphorylation in mouse or rat whole blood evoked by anti-IgD

\begin{tabular}{lccccc}
\hline \multirow{2}{*}{ Animal } & \multirow{2}{*}{ Cell Type } & \multicolumn{4}{c}{ TAS05567 $(\mu \mathrm{M})$} \\
\cline { 3 - 6 } & & 0.1 & 0.3 & 1 & 3 \\
\hline Mouse & CD45R/B220 $^{+}$ & $27 \%$ & $67 \%$ & $95 \%$ & NA \\
Rat & CD45RA $^{+}$ & NA & $49 \%$ & $82 \%$ & $104 \%$ \\
\hline
\end{tabular}

NA, Not applicable. 
A

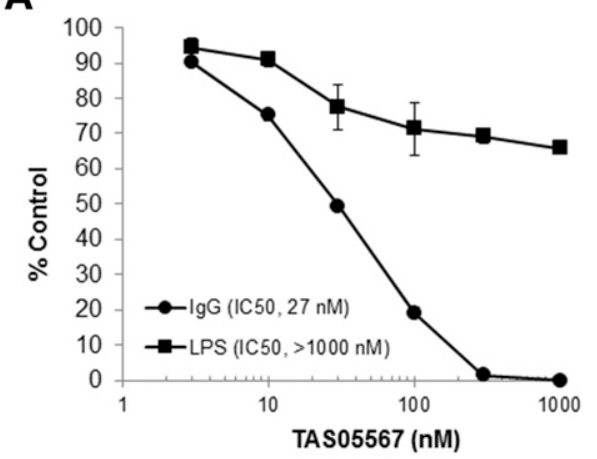

C

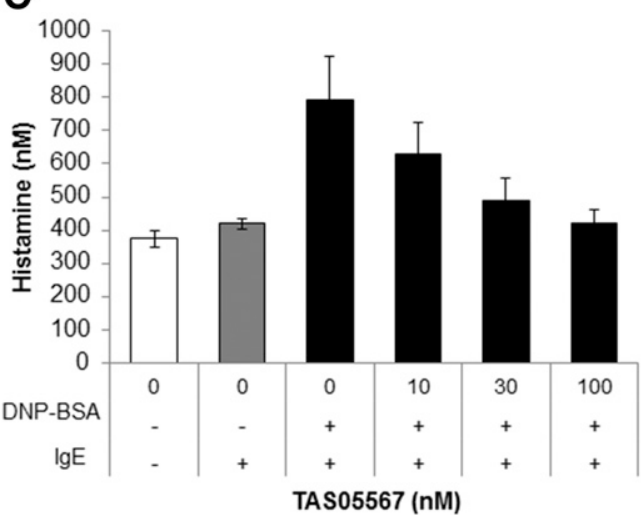

B

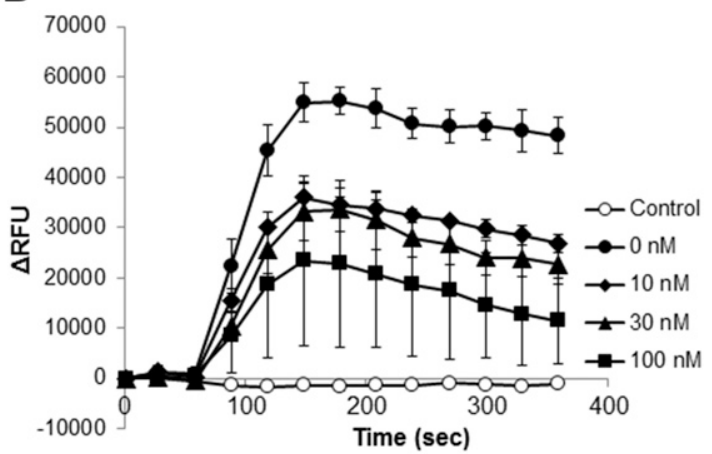

Fig. 3. Functional activity of TAS05567 in cell-based assays. (A) THP-1 cells were seeded in a microwell plate coated with purified human IgG and incubated for 4 hours in the presence of increasing concentrations of TAS05567 (circles). THP-1 cells were seeded in an uncoated plate and then stimulated with LPS for 24 hours in the presence of increasing concentrations of TAS05567 (squares). The level of TNF- $\alpha$ in the culture supernatant was measured by ELISA. (B) RBL-2H3 cells were treated with anti-DNP IgE for 1 hour. Calcium 6 kit dye and TAS05567 were added and incubated for 2 hours, followed by stimulation of cells with DNP-BSA. Monitoring of RFUs was as described in Materials and Methods. (C) RBL-2H3 cells were treated with anti-DNP IgE for 1 hour. The sensitized cells were then pretreated with TAS05567 for 1 hour, then stimulated with DNP-BSA for 15 minutes. Histamine content in the supernatant was measured using a histamine enzyme immunoassay (EIA) kit. Data were obtained from triplicate analyses and are presented as mean \pm S.D.

peripheral blood B cells of mice and rats in a concentrationdependent manner (Table 2), with estimated $\mathrm{IC}_{50}$ values of approximately 0.2 and $0.3 \mu \mathrm{M}$, respectively. We also determined the plasma protein binding of TAS05567 using mouse, rat, and human plasma. The mean unbound fraction of TAS 05567 in plasma was $15.4 \%$ in mouse, $18.3 \%$ in rat, and $21.9 \%$ in human (Supplemental Table 3), and therefore the plasma protein binding of TAS05567 was almost the same level between rodents and human.

By integrating the whole-blood assay results with singledose pharmacokinetic data, we calculated the estimated duration of Syk inhibition by TAS05567 in vivo. In mice, the plasma TAS05567 concentration was $0.47 \mu \mathrm{M}$ at 6 hours after administration of $10 \mathrm{mg} / \mathrm{kg}$, indicating that it was above the $\mathrm{IC}_{50}$ in the mouse whole-blood assay for more than 6 hours (Fig. 5A). When rats were administered TAS05567 at doses of 10 or $25 \mathrm{mg} / \mathrm{kg}$, the plasma concentration remained above the $\mathrm{IC}_{50}$ in the rat whole-blood assay for approximately 8 and 18 hours, respectively (Fig. 5B).

TAS05567 Suppresses Disease Progression in a Mouse Model of Collagen Antibody-Induced Arthritis. To investigate the potential therapeutic value of TAS05567 for $\mathrm{RA}$, we evaluated its effects in a representative rodent model of arthritis. Collagen antibody-induced arthritis (CAIA) is mediated primarily by innate immune systems; in particular, Fc $\gamma$ R-bearing cells are implicated in antibody-mediated inflammation in the joints (Nandakumar et al., 2003). When administered orally at doses of 10 and $30 \mathrm{mg} / \mathrm{kg}$ per day for 9 days starting from day 0, TAS05567 inhibited the development of arthritis on the basis of clinical scores, with complete inhibition at $30 \mathrm{mg} / \mathrm{kg}$ (>90\% inhibition; Fig. $6 \mathrm{~A})$. In addition, serum MMP-3 levels were significantly lower in both the 10 and $30 \mathrm{mg} / \mathrm{kg}$ TAS05567 groups than in the vehicle group (Fig. 6B).

TAS05567 Improves Symptoms in a Rat Model of Established Collagen-Induced Arthritis. We also assessed the effect of TAS05567 using a collagen-induced arthritis (CIA) model because of its similar pathogenetic mechanism to human RA owing to involvement of several immune cells, including T cells, B cells, and macrophages (Joe et al., 1999). In this experiment, we tested rats with CIA using a therapeutic dosing regimen to explore the therapeutic potential of TAS05567. Rats with a significant increase in foot pad volume (indicating paw swelling) were randomly assigned to the vehicle or TAS05567 groups. Although there was no significant improvement in the $4-\mathrm{mg} / \mathrm{kg}$ TAS05567 group, treatment with TAS05567 at doses of 10 and $25 \mathrm{mg} / \mathrm{kg}$ resulted in significant reduction of joint inflammation (Table 3). In addition, histopathologic examination of the left and right hind paws revealed significant reduction of inflammatory cell infiltration into the synovium and pannus formation in both the 10 and $25 \mathrm{mg} / \mathrm{kg}$ TAS05567 groups (Fig. 7, A and B). At these doses, TAS05567 also markedly 
A

(-) RANKL

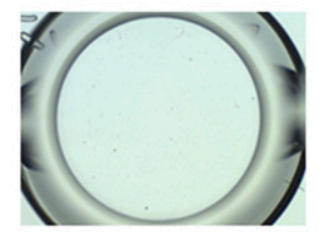

TAS05567 1 nM

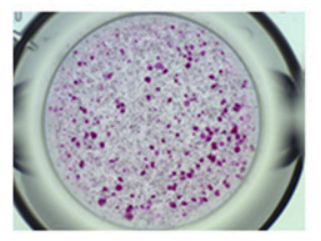

TAS05567 10nM

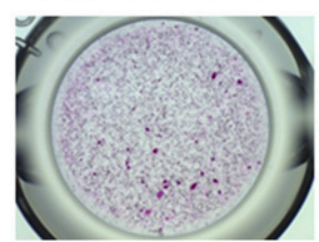

(+) RANKL

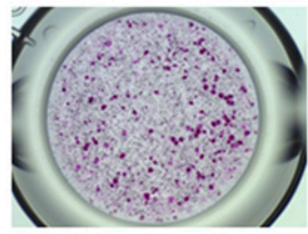

TAS05567 3nM

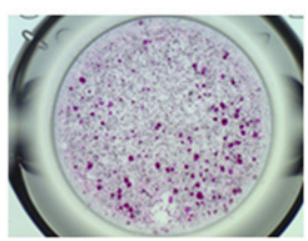

TAS05567 30 nM

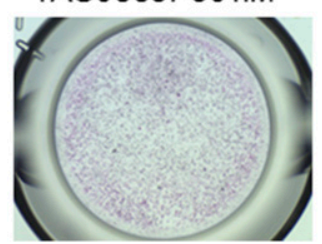

B

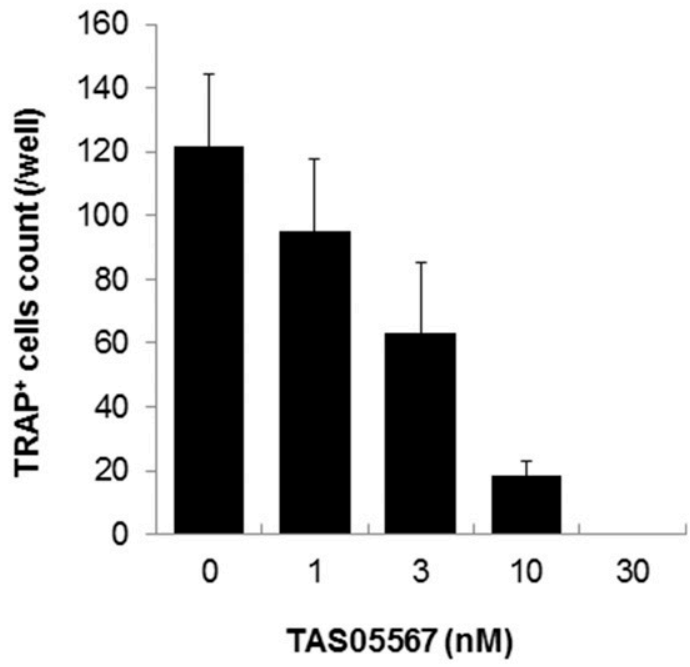

Fig. 4. TAS05567 inhibits osteoclastogenesis in a concentration-dependent manner. (A) Representative images of TRAP staining showing M-CSF and RANKL-mediated mature osteoclast differentiation from human osteoclast precursors. Negative control and positive control wells are labeled as (-) RANKL (upper left) and (+) RANKL (upper right), respectively. TAS05567 concentration is labeled on the upper portion of each image. (B) The total number of TRAP-positive osteoclasts per well was determined by manual counting. Data were obtained from triplicate analyses and are presented as mean \pm S.D.

ameliorated damage to cartilage and bone (Fig. 7, A and B). Moreover, we evaluated the serum level of COMP, an extracellular matrix glycoprotein associated with disease activity and cartilage damage in RA patients (Joosten et al., 1999). TAS05567 reduced serum COMP levels in a dosedependent manner (Fig. 7C). Finally, we monitored changes in body weight during treatment as an index of general toxicity and assessed red blood cell count and hemoglobin levels, because anemia was observed in some patients during clinical trials of drugs with JAK2 inhibition (Sonbol et al., 2013). As shown in Fig. 8A, the change in body weight was similar between TAS05567-treated CIA rats and naïve rats. Body weight was higher in TAS05567-treated rats owing to amelioration of systemic inflammation in comparison with vehicletreated rats. In addition, TAS05567 did not significantly reduce the red blood cell count or hemoglobin level in any dose group compared with the vehicle-treated controls (Fig. 8, $\mathrm{B}$ and $\mathrm{C})$.

TAS05567 Ameliorates Thrombocytopenia in a Mouse Model of ITP. ITP is an autoantibody-mediated disorder in which IgG binds to platelets and causes their accelerated clearance via Fc $\gamma \mathrm{R}$ expressed on macrophages (Crow and Lazarus, 2003). TAS05567 inhibited Fc $\gamma$ Rdependent phagocytosis in macrophages (Supplemental Fig. 2). Accordingly, we examined whether TAS05567 could attenuate platelet count decreases in mice with thrombocytopenia induced by administration of an antiplatelet antibody. In mice injected with an anti-CD41 antibody, the platelet count decreased by more than $50 \%$ compared with sham mice, whereas the platelet count in IVIg-treated mice was significantly higher than that of vehicle-treated mice (Fig. 9).
In this model, TAS05567 provided significant protection against anti-CD41 antibody-induced thrombocytopenia in a dose-dependent manner and completely prevented thrombocytopenia when administered at $100 \mathrm{mg} / \mathrm{kg}$ (Fig. 9). Some signs of toxicity, such as body weight loss and lower locomotor activity, were not observed during the treatment period (data not shown).

TAS05567 Attenuates IgE Crosslinking-Induced Skin Lesions in TNP-IgE Transgenic Mice. In the cell-based assay, TAS05567 inhibited histamine release from IgEsensitized RBL-2H3 cells stimulated with antigen (Fig. 3C). We therefore evaluated the effects of TAS05567 on IgEdependent allergic reactions in vivo using TNP-IgE transgenic mice. Administration of picryl chloride to the ears of

TABLE 3

Therapeutic effects of TAS05567 on antiarthritic activity in collageninduced arthritis in rat

Data are presented as mean \pm S.E.M.; $n=6$ rats in the naïve group; $n=9$ rats each in the vehicle and treatment groups.

\begin{tabular}{|c|c|c|c|}
\hline \multirow{2}{*}{ Group } & \multicolumn{3}{|c|}{ Hind Paw Volume (ml) } \\
\hline & Day 1 & Day 8 & Day 14 \\
\hline Naive & $2.31 \pm 0.03$ & $2.31 \pm 0.05$ & $2.28 \pm 0.05$ \\
\hline Vehicle & $2.56 \pm 0.07^{a}$ & $2.88 \pm 0.12$ & $2.92 \pm 0.13$ \\
\hline TAS05567 (4 mg/kg) & $2.55 \pm 0.08$ & $2.63 \pm 0.08$ & $2.66 \pm 0.12$ \\
\hline TAS05567 (10 mg/kg) & $2.60 \pm 0.10$ & $2.41 \pm 0.04^{b}$ & $2.34 \pm 0.03^{c}$ \\
\hline TAS05567 (25 mg/kg) & $2.54 \pm 0.07$ & $2.34 \pm 0.04^{c}$ & $2.33 \pm 0.03^{c}$ \\
\hline Prednisolone $(3 \mathrm{mg} / \mathrm{kg})$ & $2.54 \pm 0.06$ & $2.44 \pm 0.03^{c}$ & $2.47 \pm 0.05^{c}$ \\
\hline
\end{tabular}

${ }^{a} P<0.01$ compared with the naïve group

${ }^{b} P<0.05$ compared with the vehicle group.

${ }^{c} P<0.01$ compared with the vehicle group. 
A

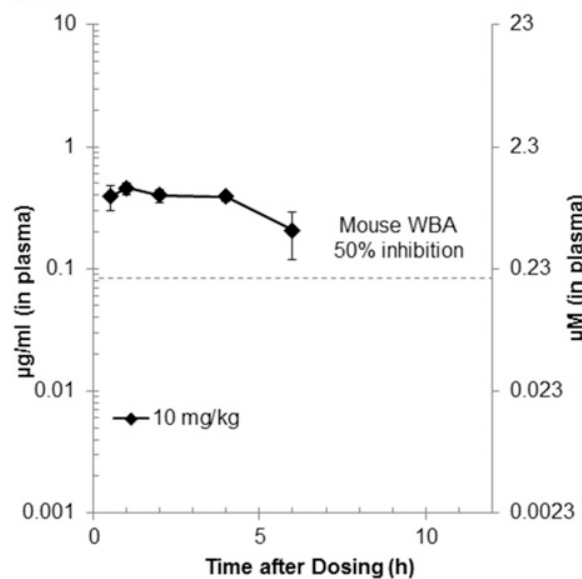

B

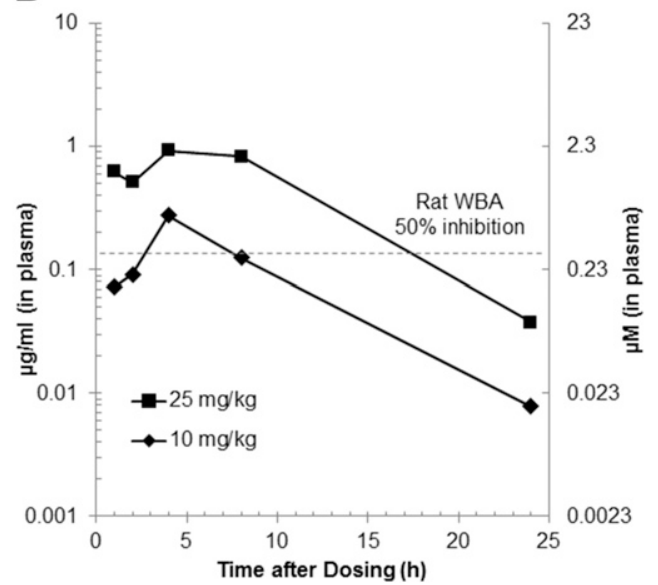

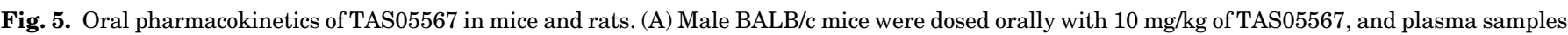

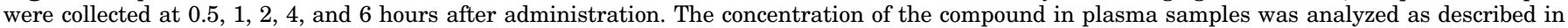

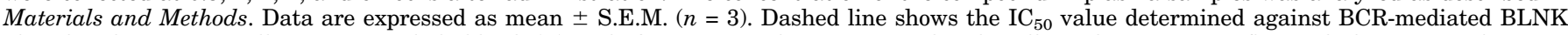

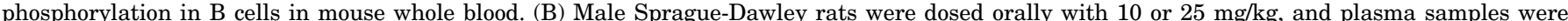

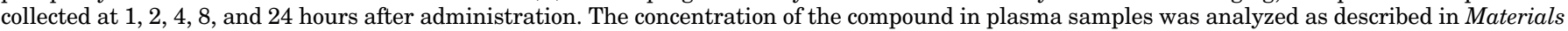

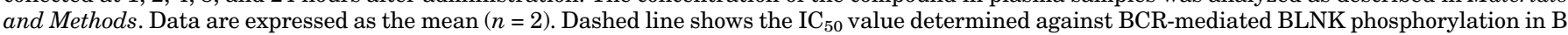
cells in rat whole blood. WBA, whole-blood assay.

TNP-IgE transgenic mice provoked ear swelling, which reached a peak 2 hours after antigen challenge (immediate phase), and swelling was observed even after 24 hours (late phase) (Fig. 10). TNP-IgE transgenic mice were treated orally with a single dose of TAS 05567 (10 or $25 \mathrm{mg} / \mathrm{kg}$ ) 30 minutes before antigen challenge. As shown in Fig. 10, TAS05567 strongly suppressed ear swelling from 1 to 4 hours after challenge but did not show significant effect on swelling at 24 hours.

\section{Discussion}

Syk plays an essential role in the BCR-, FcR-, and integrinsignaling cascades, which are involved in triggering multiple inflammatory responses (Mocsai et al., 2010; Deng et al., 2016). In addition, the immunomodulatory adaptor proteins DAP12 and Fc $\gamma R$ activate Syk to regulate osteoclast function (Mocsai et al., 2004). Thus, several lines of evidence suggest that pharmacologic inhibition of Syk activation could reduce immune-mediated responses in a wide range of inflammatory disorders. In the present study, we determined the pharmacologic profile of a novel selective Syk inhibitor, TAS05567, which potently inhibited BCR signaling and FcR-dependent cellular functions. TAS05567 also inhibited osteoclast differentiation in the presence of M-CSF and RANKL. After oral administration, TAS05567 was well-tolerated and ameliorated symptoms in animal models of RA and ITP. We further demonstrated that
A

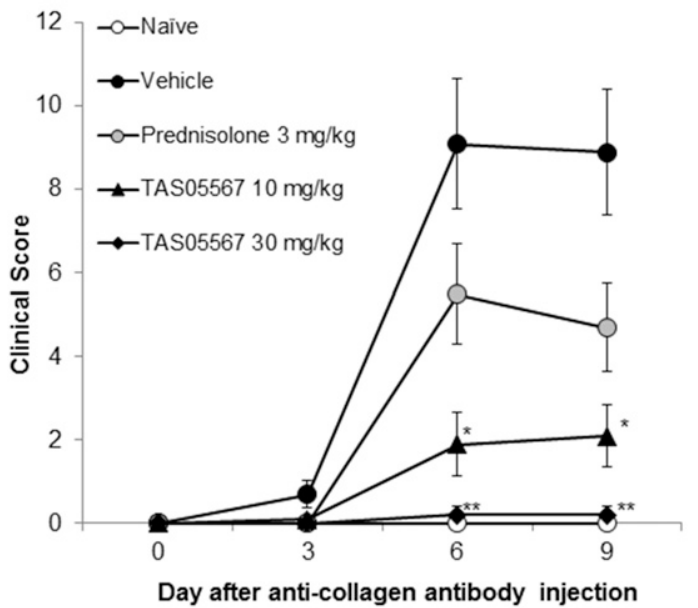

B

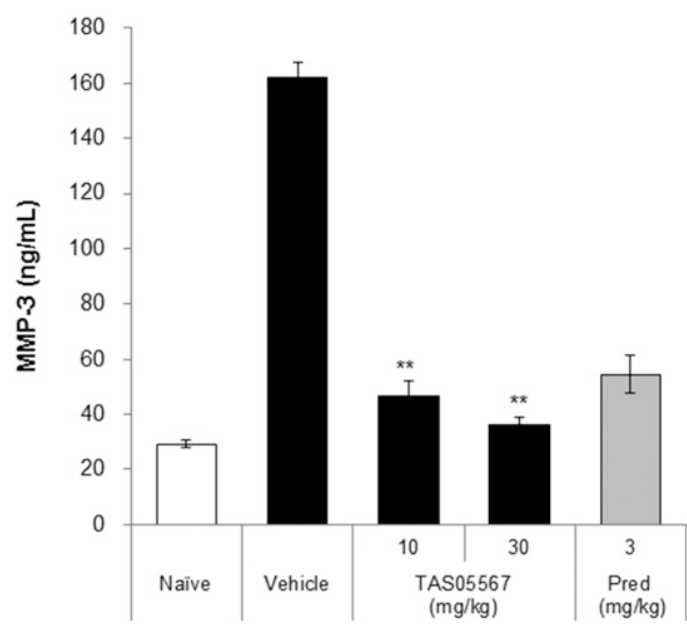

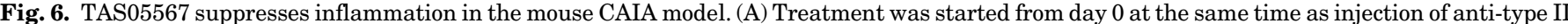

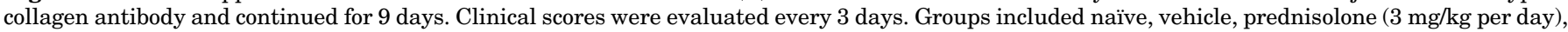

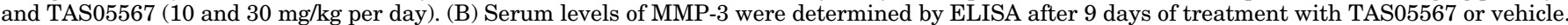
Data are presented as mean \pm S.E.M. $\left(n=10\right.$ per group). ${ }^{*} P<0.05 ; * * P<0.01$ compared with the vehicle group. 
A

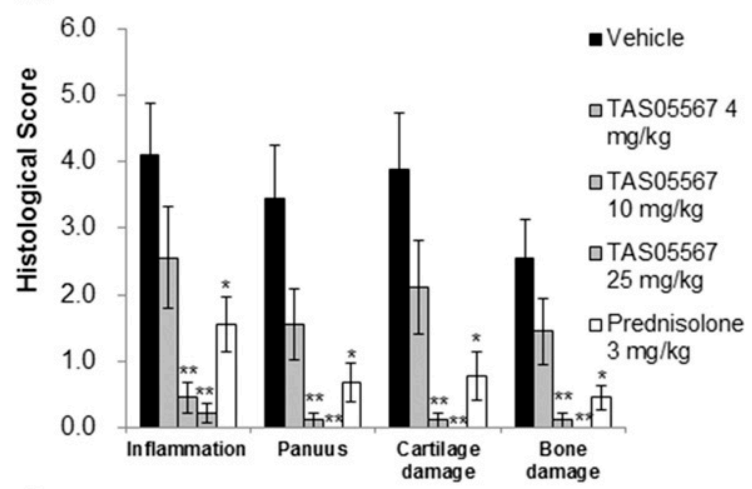

C

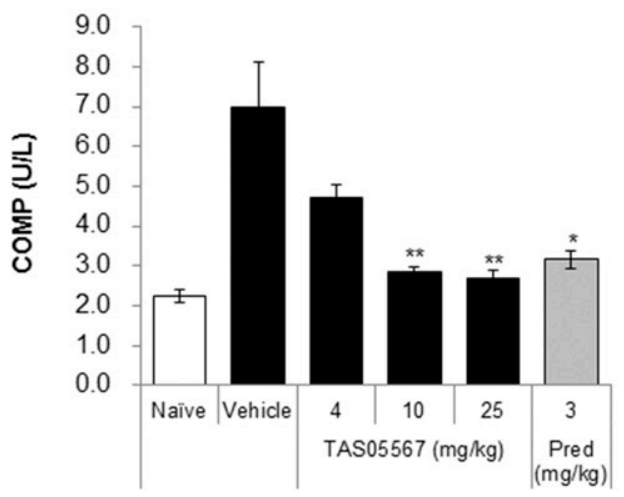

B

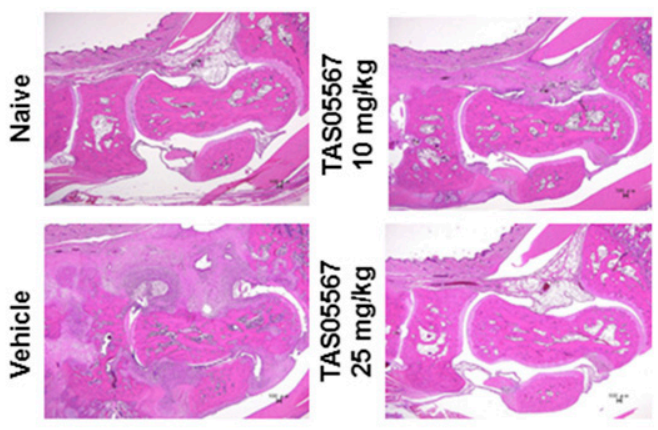

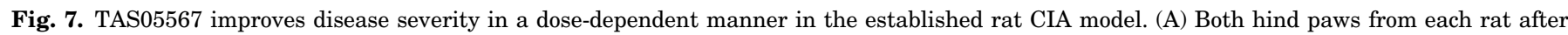

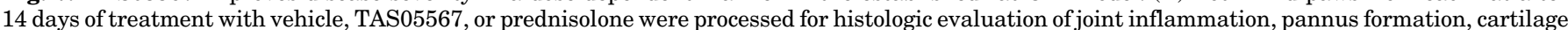

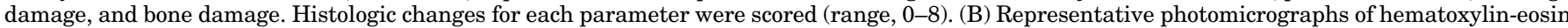

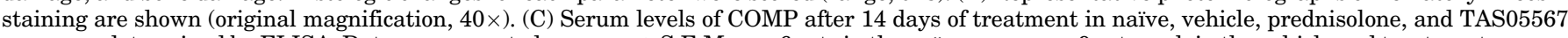

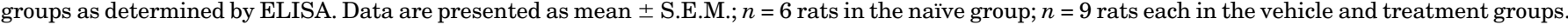
${ }^{*} P<0.05 ; * * P<0.01$ compared with the vehicle group.

TAS05567 suppresses IgE-mediated allergic responses in vivo.

Our biochemical assays revealed that R406 inhibits the activity of several protein kinases, including VEGFR2 and JAK2, that are associated with increased risk of hypertension and anemia (Verstovsek, 2010; Hayman et al., 2012). Among several inhibitors of Syk kinase activity currently under development, fostamatinib has demonstrated effectiveness for ITP in phase III trials (http://ir.rigel.com/phoenix.zhtml? $c=120936 \& p=$ irol-newsArticle \&ID = 2198145), but hypertension was more frequent in the fostamatinib group than in the placebo group during clinical trials examining RA treatment (Lengel et al., 2015). In addition, anemia was observed in patients treated with tofacitinib and baricitinib owing to inhibition of JAK2 kinase activity (Lundquist et al., 2014; Zhang et al., 2017). Compared with R406, TAS05567 not only showed lower activity against theses kinases but also displayed more potent inhibition of Syk activity. In the rat model of established CIA, body weight and hematology parameters for anemia were not affected by 2 weeks of treatment with TAS05567, suggesting that it is well-tolerated. In addition to assessing selectivity for protein kinases, we performed cellular assays to obtain data about targeting of the immune system by TAS05567. We found that whereas TAS05567 markedly reduces Fc $\gamma$ R-mediated TNF- $\alpha$ production by THP-1 cells, it has minimal effect on the response to TLR4 stimulation. Innate immune responses mediated through
TLR4, which is expressed primarily on monocytes and neutrophils, are associated with host defenses against microbial infection, particularly infection by Gram-negative bacteria (Matsuura, 2013). Therefore, this feature of TAS05567 could be an advantage for treating autoimmune diseases such as RA because an increased risk of infection has been a major issue with conventional therapies (Scott, 2012; Wollenhaupt et al., 2014). To delineate the toxicity profile of TAS05567 in detail, further toxicity studies in rodents or nonrodent species will be required.

In the joints of patients with RA, autoantibodies form immune complexes (ICs) that interact with FcRs expressed on synovial immune cells to induce production of proinflammatory cytokines, resulting in disease progression (Tan Sardjono et al., 2003). As with human RA, anti-type II collagen antibodies form ICs that activate $\mathrm{Fc} \gamma \mathrm{Rs}$ on macrophages and monocytes in animal models, causing synovitis in CAIA and CIA (Burkhardt et al., 2002; Nandakumar et al., 2003). Consistent with the inhibitory effect of TAS05567 on FcRmediated immune responses in vitro, treatment with this drug suppressed paw swelling in a dose-dependent manner in both rodent models. Of note, in pharmacokinetic studies and wholeblood assays, the robust effect of TAS05567 in these arthritis models was achieved without continuous inhibition of the target, which is consistent with a previous report (Coffey et al., 2012). Therefore, TAS05567 may provide significant benefit for patients with RA at doses that partially suppress Syk 

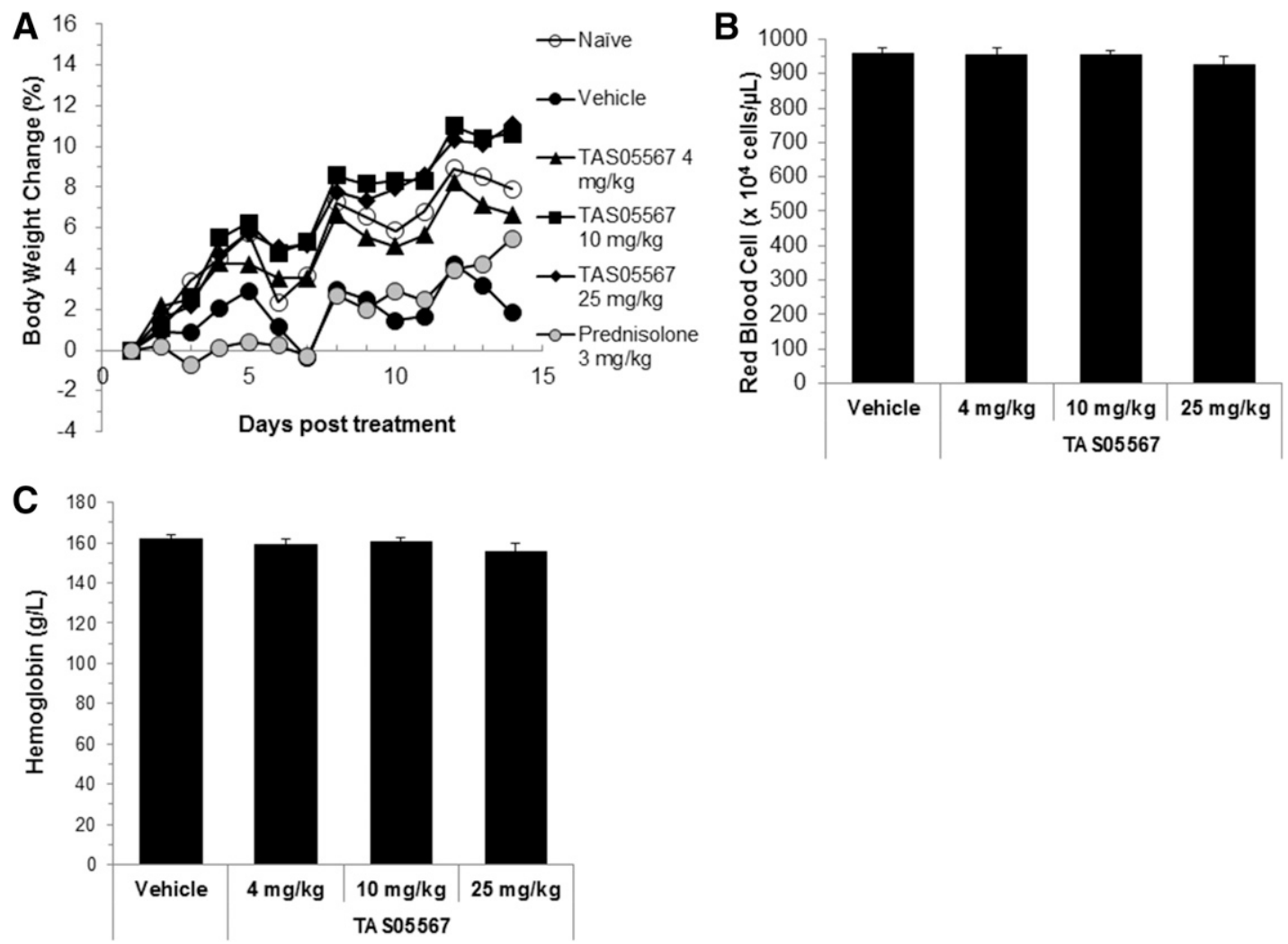

Fig. 8. TAS05667 does not affect body weight, red blood cell count, or hemoglobin level in the established rat CIA model. (A) CIA rats with clinical sings of paw swelling were randomized at day 1 . Treatment was started from day 1 and continued for 14 days. Changes in body weight of the rats were monitored every day. Body weight changes (0\% at day 1) for each group are presented as average values. Peripheral blood samples were obtained from the rats and analyzed for changes in red blood cell count (B) and hemoglobin level (C). Data are presented as mean \pm S.E.M.; $n=6$ rats in the naïve group; $n=9$ rats each in the vehicle and treatment groups.

activity, thus mitigating the toxic effects associated with complete genetic deletion of Syk.

This study demonstrated that TAS05567 strongly suppresses damage to bone in a rat model of established CIA. Syk is recruited and phosphorylated as a result of the RANKL-RANK interaction, after which it induces activation of c-Fos and nuclear factor of activated T cells cytoplasmic 1 , leading to differentiation of functional osteoclasts (Kim et al., 2015). Consistent with findings obtained in Sykdeficient cells (Mocsai et al., 2004), in the present study, TAS05567 blocked the differentiation of mature osteoclasts from immature cells in the presence of RANKL. Additionally, histologic improvement was observed in ankle joints of TAS05567-treated CIA rats, and the serum COMP concentration decreased to almost the same levels as that in naïve rats. Several studies have shown that elevation of the serum COMP level reflects joint damage, particularly cartilage degradation (Joosten et al., 1999; Tseng et al., 2009). Furthermore, TAS05567 reduced the serum MMP-3 level in CAIA mice in the present study. MMP-3 plays a pivotal role in the degradation of cartilage components, and this enzyme is produced when synovial cells are stimulated by proinflammatory cytokines such as TNF- $\alpha$ and interleukin$1 \beta$ (Kelley et al., 2007). Indeed, it was reported that $\mathrm{R} 406$ blocks TNF- $\alpha$-induced MMP-3 production in fibroblast-like synoviocytes from RA patients by suppressing Syk pathway activation (Cha et al., 2006). Thus, improvement of cartilage damage in our rat CIA model may have been associated with suppression of MMP-3 production by TAS05567, although the serum MMP-3 level was not determined in this study. Taken together, these findings suggest that TAS05567 would be useful for alleviating both progressive bone erosion and cartilage damage in RA.

In addition to its potential usefulness for treating RA, TAS05567 inhibited Fc $\gamma$ R-dependent phagocytosis in macrophages and exhibited significant efficacy in a representative animal model of ITP at the same dosage used in the mouse arthritis model. Lu et al. (2011) reported that decreasing Syk expression in macrophages by transfection with Syk-specific siRNA attenuates antibody-mediated phagocytosis, a finding that is consistent with our data. Of note, treatment with TAS05567 at $100 \mathrm{mg} / \mathrm{kg}$ completely prevented the induction of thrombocytopenia by injection of anti-CD41 antibody in the present study. Fostamatinib also showed efficacy in a similar model of ITP, but it only partially prevented thrombocytopenia even at the highest dose (Podolanczuk et al., 2009). Fostamatinib was also reported to be effective against refractory ITP in clinical trials, but not all patients responded to it. Considering the balance between efficacy and safety, $100 \mathrm{mg} / \mathrm{kg}$ may be too high a dose of TAS05567, even though no toxicity was observed during the treatment period. However, TAS05567 has much higher selectivity for the target enzyme than does fostamatinib, suggesting that TAS 05567 would be better tolerated and could be used at higher doses without causing off-target side effects. 


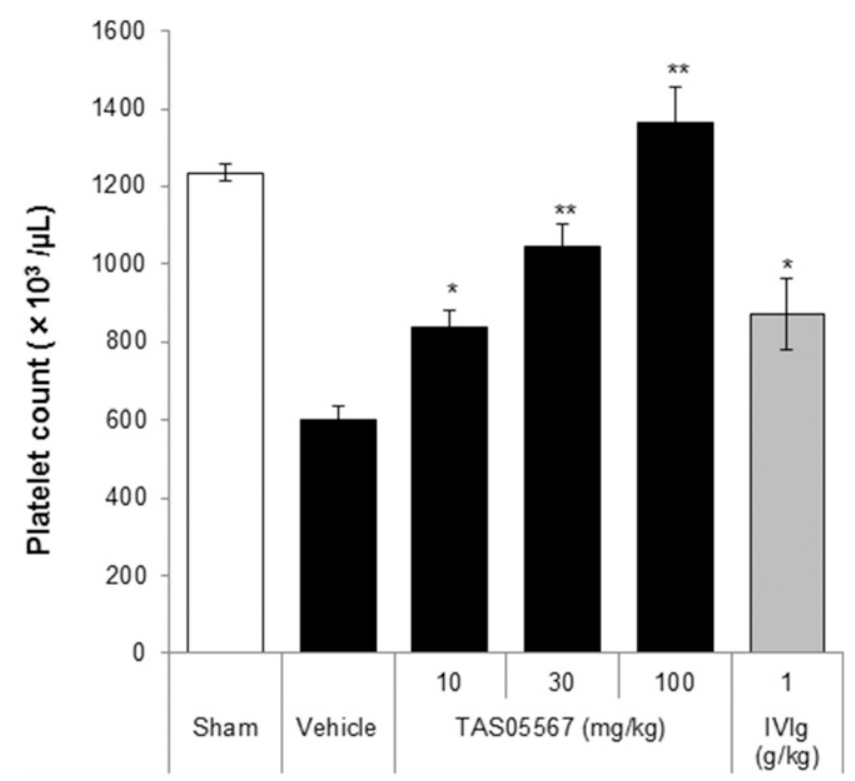

Fig. 9. TAS 05567 protects mice from anti-platelet antibody-induced thrombocytopenia. Mice were treated with TAS05567 $(10,30,100 \mathrm{mg} /$ $\mathrm{kg}$ ) on days 1 and 2 . For the IVIg group, mice were intravenously injected with $1 \mathrm{~g} / \mathrm{kg}$ IVIg once on day 1 only. On day 2 , mice were intravenously injected with anti-CD41 antibody. Platelet counts were evaluated 24 hours later. Data are presented as mean \pm S.E.M.; $n=5$ or 6 per group. ${ }^{*} P<$ $0.05 ; * * P<0.01$ compared with the vehicle group.

Type I allergic diseases such as urticaria, asthma, and allergic rhinitis are caused and exacerbated by IgE-mediated allergic reactions (Galli and Tsai, 2012; Navines-Ferrer et al., 2016). Antigen-specific IgE bound to FceRI on mast cells induces the release of chemical mediators such as histamine, causing the early symptoms of an allergic reaction (Stone et al., 2010). Therefore, the symptoms of type I allergic diseases are typically alleviated with antihistamine drugs. As Syk acts upstream of signaling cascades induced by $\operatorname{IgE}$ crosslinking, TAS05567 potently inhibited the antigen/IgEtriggered intracellular calcium flux as well as histamine release in vitro. We further demonstrated the ability of TAS05567 to suppress immediate IgE-mediated allergic reactions in vivo using TNP-specific IgE transgenic mice. Unexpectedly, TAS05567 did not show a significant response in the late phase. One possible reason may be insufficient concentration of TAS05567 to suppress the inflammation in this phase because its concentration at 24 hours after the administration was lower than the $\mathrm{IC}_{50}$ value of the whole blood assay even at $25 \mathrm{mg} / \mathrm{kg}$ (data not shown). Another possible reason is that IgE-mediated chemical mediator secretion through Syk activation contributes to the immediate allergic response, but the delayed response might depend on other signaling cascades (e.g., T-cell receptor signaling). Indeed, the immediate ear swelling caused by epicutaneous antigen challenge in this mouse model can be attributed primarily to a series of chemical mediators, including histamine, and thus, administration of an antihistamine inhibitor blocks the allergic response within a few hours post-antigen challenge. However, the antihistamine agent does not improve symptoms in the late phase, whereas cyclosporine A markedly inhibits ear swelling only in this phase (Sato et al., 2003). With respect to inhibition of immediate allergic responses, TAS05567 might be more potent than conventional

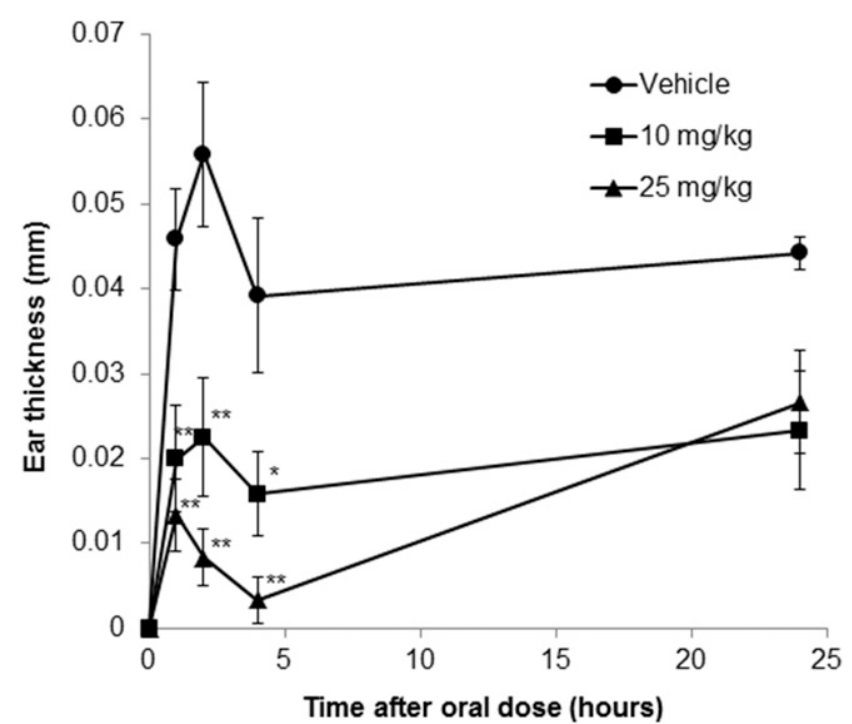

Fig. 10. TAS 05567 blocks the increase in ear thickness in TNP-IgE transgenic mice. TNP-specific IgE transgenic mice were treated with TAS05567 (10, $25 \mathrm{mg} / \mathrm{kg}) 30$ minutes before epicutaneous administration of $0.025 \%$ picryl chloride. Ear thickness was measured at 1, 2, 4, and 24 hours after antigen challenge. Difference in ear thickness (average value on the right and left) was calculated at each time point. Data are presented as mean \pm S.E.M.; $n=6$ per group. ${ }^{*} P<0.05 ; * * P<0.01$ compared with the vehicle group.

drugs that target a single chemical mediator, because Syk inhibition concomitantly suppresses secretion of multiple factors from mast cells, including histamine, arachidonate metabolites, and cytokines (Kato et al., 2017). From these findings, we expect that combination therapies including TAS05567 and inhibitors targeting T-cell function, such as cyclosporine A, will prove highly efficacious in the treatment of type I allergic diseases.

In summary, TAS05567, a novel, potent, selective, and orally active Syk kinase inhibitor, strongly inhibits the enzyme's activity in IC-dependent cellular systems. TAS05567 also showed good efficacy in our animal models of RA and ITP and alleviated allergic skin inflammation in vivo. Notably, TAS05567 showed less off-target activity than R406, such as VEGFR2 and JAK2 inhibition, suggesting that the efficacy/ toxicity profiles of our Syk inhibitor and fostamatinib differ. Our data suggest that TAS05567 would be an efficacious novel treatment of Ig-mediated inflammatory diseases, including RA, ITP, and type I allergic diseases.

\section{Acknowledgments}

The authors thank Yasuhiro Yasutomi and Dr. Fumihito Hosoi for fruitful discussions and review of this manuscript. All authors were employees of Taiho Pharmaceutical Co. during the preparation of the manuscript and declare that they have no competing financial interests.

\section{Authorship Contributions}

Participated in research design: Hayashi, Harada, Sasaki.

Conducted experiments: Hayashi, Kaneko, Demizu, Akasaka, Tayama, Harada, Irie.

Contributed new reagents or analytic tools: Kaneko, Ogino. Performed data analysis: Hayashi, Harada, Irie, Ogino, Fujino.

Wrote or contributed to the writing of the manuscript: Hayashi, Kaneko, Ogino, Sasaki. 


\section{References}

Arnold DM (2015) Bleeding complications in immune thrombocytopenia. Hematology (Am Soc Hematol Educ Program) 2015:237-242.

Bajpai M (2009) Fostamatinib, a Syk inhibitor prodrug for the treatment of inflammatory diseases. IDrugs 12:174-185.

Baluom M, Grossbard EB, Mant T, and Lau DT (2013) Pharmacokinetics of fostamatinib, a spleen tyrosine kinase (SYK) inhibitor, in healthy human subjects following single and multiple oral dosing in three phase I studies. $\mathrm{Br} \mathrm{J} \mathrm{Clin}$ Pharmacol 76:78-88.

Banda NK, Thurman JM, Kraus D, Wood A, Carroll MC, Arend WP, and Holers VM (2006) Alternative complement pathway activation is essential for inflammation and joint destruction in the passive transfer model of collagen-induced arthritis. $J$ Immunol 177:1904-1912.

Braselmann S, Taylor V, Zhao H, Wang S, Sylvain C, Baluom M, Qu K, Herlaar E Lau A, Young C, et al. (2006) R406, an orally available spleen tyrosine kinase inhibitor blocks fc receptor signaling and reduces immune complex-mediated inflammation. J Pharmacol Exp Ther 319:998-1008.

Burke RT, Meadows S, Loriaux MM, Currie KS, Mitchell SA, Maciejewski P, Clarke AS, Dipaolo JA, Druker BJ, Lannutti BJ, and Spurgeon SE (2014) A potential therapeutic strategy for chronic lymphocytic leukemia by combining Idelalisib and GS-9973, a novel spleen tyrosine kinase (Syk) inhibitor. Oncotarget 5(4):908-15.

Burkhardt H, Koller T, Engström A, Nandakumar KS, Turnay J, Kraetsch HG, Kalden JR, and Holmdahl R (2002) Epitope-specific recognition of type II collagen by rheumatoid arthritis antibodies is shared with recognition by antibodies that are arthritogenic in collagen-induced arthritis in the mouse. Arthritis Rheum 46 2339-2348.

Cha HS, Boyle DL, Inoue T, Schoot R, Tak PP, Pine P, and Firestein GS (2006) A novel spleen tyrosine kinase inhibitor blocks c-Jun N-terminal kinase-mediated gene expression in synoviocytes. J Pharmacol Exp Ther 317:571-578.

Coffey G, DeGuzman F, Inagaki M, Pak Y, Delaney SM, Ives D, Betz A, Jia ZJ, Pandey A, Baker D, et al. (2012) Specific inhibition of spleen tyrosine kinase suppresses leukocyte immune function and inflammation in animal models of rheumatoid arthritis. J Pharmacol Exp Ther 340:350-359.

Costello PS, Turner M, Walters AE, Cunningham CN, Bauer PH, Downward J, and Tybulewicz VL (1996) Critical role for the tyrosine kinase Syk in signalling through the high affinity IgE receptor of mast cells. Oncogene 13:2595-2605.

Crow AR and Lazarus AH (2003) Role of Fcgamma receptors in the pathogenesis and treatment of idiopathic thrombocytopenic purpura. J Pediatr Hematol Oncol 25 (Suppl 1):S14-S18.

D'Amato G, Salzillo A, Piccolo A, D'Amato M, and Liccardi G (2007) A review of anti$\mathrm{IgE}$ monoclonal antibody (omalizumab) as add on therapy for severe allergic ( $\mathrm{IgE}$ mediated) asthma. Ther Clin Risk Manag 3:613-619.

Debré M, Bonnet MC, Fridman WH, Carosella E, Philippe N, Reinert P, Vilmer E, Kaplan C, Teillaud JL, and Griscelli C (1993) Infusion of Fc gamma fragments for treatment of children with acute immune thrombocytopenic purpura. Lancet 342 : 945-949.

Deng GM, Kyttaris VC, and Tsokos GC (2016) Targeting Syk in Autoimmune Rheumatic Diseases. Front Immunol 7:78.

Ferguson GD, Delgado M, Plantevin-Krenitsky V, Jensen-Pergakes K, Bates RJ, Torres S, Celeridad M, Brown H, Burnett K, Nadolny L, et al. (2016) A novel triazolopyridine-based spleen tyrosine kinase inhibitor that arrests joint inflammation. PLoS One 11:e0145705.

Galli SJ and Tsai M (2012) IgE and mast cells in allergic disease. Nat Med 18: 693-704.

Guilliams M, Bruhns P, Saeys Y, Hammad H, and Lambrecht BN (2014) The function of Fc $\gamma$ receptors in dendritic cells and macrophages. Nat Rev Immunol 14:94-108.

Hayman SR, Leung N, Grande JP, and Garovic VD (2012) VEGF inhibition, hypertension, and renal toxicity. Curr Oncol Rep 14:285-294.

Huang ZY, Kim MK, Kim-Han TH, Indik ZK, and Schreiber AD (2013) Effect of locally administered Syk siRNA on allergen-induced arthritis and asthma. Mol Immunol 53:52-59.

Joe B, Griffiths MM, Remmers EF, and Wilder RL (1999) Animal models of rheumatoid arthritis and related inflammation. Curr Rheumatol Rep 1:139-148.

Joosten LA, Lubberts E, Helsen MM, Saxne T, Coenen-de Roo CJ, Heinegård D, and van den Berg WB (1999) Protection against cartilage and bone destruction by systemic interleukin-4 treatment in established murine type II collagen-induced arthritis. Arthritis Res 1:81-91.

Kagari T, Tanaka D, Doi H, and Shimozato T (2003) Essential role of Fc gamma receptors in anti-type II collagen antibody-induced arthritis. J Immunol 170: 4318-4324.

Kato T, Iwasaki H, Kobayashi H, Miyagawa N, Matsuo A, Hata T, and Matsushita M (2017) JTE-852, a novel spleen tyrosine kinase inhibitor, blocks mediator secretion from mast cells with immunoglobulin E crosslinking. Eur J Pharmacol 801:1-8.

Kelley MJ, Rose AY, Song K, Chen Y, Bradley JM, Rookhuizen D, and Acott TS (2007) Synergism of TNF and IL-1 in the induction of matrix metalloproteinase-3 in trabecular meshwork. Invest Ophthalmol Vis Sci 48:2634-2643.

Kiefer F, Brumell J, Al-Alawi N, Latour S, Cheng A, Veillette A, Grinstein S, and Pawson T (1998) The Syk protein tyrosine kinase is essential for Fcgamma receptor signaling in macrophages and neutrophils. Mol Cell Biol 18:4209-4220.

Kim JY, Park SH, Baek JM, Erkhembaatar M, Kim MS, Yoon KH, Oh J, and Lee MS (2015) Harpagoside inhibits RANKL-induced osteoclastogenesis via Syk-Btk$\mathrm{PLC} \gamma 2-\mathrm{Ca}(2+)$ signaling pathway and prevents inflammation-mediated bone loss. J Nat Prod 78:2167-2174.

Kitagawa D, Yokota K, and Gouda M (2013) Activity-Based Kinase Profiling of Approved Tyrosine Kinase Inhibitors. Genes Cells 18:110-122.

Lengel D, Lamm Bergström E, Barthlow H, Oldman K, Musgrove H, Harmer A, Valentin JP, Duffy P, Braddock M, and Curwen J (2015) Prevention of fostamatinib-induced blood pressure elevation by antihypertensive agents. Pharmacol Res Perspect $\mathbf{3}$ : e00176.
Liao C, Hsu J, Kim Y, Hu DQ, Xu D, Zhang J, Pashine A, Menke J, Whittard T, Romero N, et al. (2013) Selective inhibition of spleen tyrosine kinase (SYK) with a novel orally bioavailable small molecule inhibitor, RO9021, impinges on various innate and adaptive immune responses: implications for SYK inhibitors in autoimmune disease therapy. Arthritis Res Ther 15:R146.

Lu Y, Wang W, Mao H, Hu H, Wu Y, Chen BG, and Liu Z (2011) Antibody-mediated platelet phagocytosis by human macrophages is inhibited by siRNA specific for sequences in the SH2 tyrosine kinase, Syk. Cell Immunol 268:1-3.

Lundquist LM, Cole SW, and Sikes ML (2014) Efficacy and safety of tofacitinib for treatment of rheumatoid arthritis. World J Orthop 5:504-511.

Matsuura M (2013) Structural modifications of bacterial lipopolysaccharide that facilitate gram-negative bacteria evasion of host innate immunity. Front Immunol 4: 109.

Mócsai A, Humphrey MB, Van Ziffle JA, Hu Y, Burghardt A, Spusta SC, Majumdar S, Lanier LL, Lowell CA, and Nakamura MC (2004) The immunomodulatory adapter proteins DAP12 and Fc receptor gamma-chain (FcRgamma) regulate development of functional osteoclasts through the Syk tyrosine kinase. Proc Natl Acad Sci USA 101:6158-6163.

Mócsai A, Ruland J, and Tybulewicz VL (2010) The SYK tyrosine kinase: a crucial player in diverse biological functions. Nat Rev Immunol 10:387-402.

Nandakumar KS, Andrén M, Martinsson P, Bajtner E, Hellström S, Holmdahl R, and Kleinau S (2003) Induction of arthritis by single monoclonal IgG anti-collagen type II antibodies and enhancement of arthritis in mice lacking inhibitory FcgammaRIIB. Eur J Immunol 33:2269-2277.

Navinés-Ferrer A, Serrano-Candelas E, Molina-Molina G.J, and Martín M (2016) IgErelated chronic diseases and anti-IgE-based treatments. J Immunol Res 2016: 8163803

Neschadim A and Branch DR (2016) Mouse models for immune-mediated platelet destruction or immune thrombocytopenia (ITP). Curr Protoc Immunol 113:15 $301-153013$

Podolanczuk A, Lazarus AH, Crow AR, Grossbard E, and Bussel JB (2009) Of mice and men: an open-label pilot study for treatment of immune thrombocytopenic purpura by an inhibitor of Syk. Blood 113:3154-3160.

Sato E, Hirahara K, Wada Y, Yoshitomi T, Azuma T, Matsuoka K, Kubo S, Taya C, Yonekawa H, Karasuyama H, et al. (2003) Chronic inflammation of the skin can be induced in IgE transgenic mice by means of a single challenge of multivalent antigen. J Allergy Clin Immunol 111:143-148.

Scott DL (2012) Biologics-based therapy for the treatment of rheumatoid arthritis. Clin Pharmacol Ther 91:30-43.

Sonbol MB, Firwana B, Zarzour A, Morad M, Rana V, and Tiu RV (2013) Comprehensive review of JAK inhibitors in myeloproliferative neoplasms. Ther Adv Hematol. 4(1):15-35.

Stone KD, Prussin C, and Metcalfe DD (2010) IgE, mast cells, basophils, and eosinophils. J Allergy Clin Immunol 125 (2 Suppl 2)S73-S80.

Suurmond J and Diamond B (2015) Autoantibodies in systemic autoimmune diseases: specificity and pathogenicity. J Clin Invest 125:2194-2202.

Tan EM (1989) Antinuclear antibodies: diagnostic markers for autoimmune diseases and probes for cell biology. Adv Immunol 44:93-151.

Tan Sardjono C, Mottram PL, and Hogarth PM (2003) The role of FcgammaRIIa as an inflammatory mediator in rheumatoid arthritis and systemic lupus erythematosus. Immunol Cell Biol 81:374-381.

Taube C, Wei X, Swasey CH, Joetham A, Zarini S, Lively T, Takeda K, Loader J, Miyahara N, Kodama T, et al. (2004) Mast cells, Fc epsilon RI, and IL-13 are required for development of airway hyperresponsiveness after aerosolized allergen exposure in the absence of adjuvant. J Immunol 172:6398-6406.

Treanor B (2012) B-cell receptor: from resting state to activate. Immunology 136: 21-27.

Tseng S, Reddi AH, and Di Cesare PE (2009) Cartilage oligomeric matrix protein (COMP): a biomarker of arthritis. Biomark Insights 4:33-44.

Turner M, Schweighoffer E, Colucci F, Di Santo JP, and Tybulewicz VL (2000) Tyrosine kinase SYK: essential functions for immunoreceptor signalling. Immunol Today 21:148-154.

Verstovsek S (2010) Therapeutic potential of Janus-activated kinase-2 inhibitors for the management of myelofibrosis. Clin Cancer Res 16:1988-1996.

Vogelpoel LT, Baeten DL, de Jong EC, and den Dunnen J (2015) Control of cytokine production by human fc gamma receptors: implications for pathogen defense and autoimmunity. Front Immunol 6:79.

Wex E, Bouyssou T, Duechs MJ, Erb KJ, Gantner F, Sanderson MP, Schnapp A Stierstorfer BE, and Wollin L (2011) Induced Syk deletion leads to suppressed allergic responses but has no effect on neutrophil or monocyte migration in vivo. Eur J Immunol 41:3208-3218.

Wollenhaupt J, Silverfield J, Lee EB, Curtis JR, Wood SP, Soma K, Nduaka CI, Benda B, Gruben D, Nakamura H, et al. (2014) Safety and efficacy of tofacitinib, an oral janus kinase inhibitor, for the treatment of rheumatoid arthritis in open-label, longterm extension studies. J Rheumatol 41:837-852.

Yamasaki T, Ariyoshi W, Okinaga T, Adachi Y, Hosokawa R, Mochizuki S, Sakurai K, and Nishihara T (2014) The dectin 1 agonist curdlan regulates osteoclastogenesis by inhibiting nuclear factor of activated T cells cytoplasmic 1 (NFATc1) through Syk kinase. J Biol Chem 289:19191-19203.

Zhang X, Chua L, Ernest C, II, Macias W, Rooney T, and Tham LS (2017) Dose/ exposure-response modeling to support dosing recommendation for phase III development of baricitinib in patients with rheumatoid arthritis. CPT Pharmacometrics Syst Pharmacol 6:804-813.

Address correspondence to: Dr. Hiroaki Hayashi, Taiho Pharmaceutical Co. Ltd, 3 Okubo, Tsukuba, Ibaraki 300-2611, Japan. E-mail: hiroaki-hayashi@ taiho.co.jp 